\title{
Preconceptional Cystic Fibrosis Carrier Screening: Attitudes and Intentions of the Target Population
}

\author{
FRANCIS A.M. POPPELAARS, ${ }^{1}$ LIDEWIJ HENNEMAN,${ }^{1,2}$ HERMAN J. ADÈR, ${ }^{3}$ MARTINA C. CORNEL, ${ }^{1}$ \\ ROSELLA P.M.G. HERMENS, ${ }^{4}$ GERRIT VAN DER WAL, ${ }^{2}$ and LEO P. TEN KATE ${ }^{1}$
}

\begin{abstract}
The aim of this study was to assess the attitudes and intentions of individuals planning a pregnancy with regard to preconceptional cystic fibrosis (CF) carrier screening and to determine factors associated with a positive and negative/neutral intention to have the test. A survey, based on a questionnaire, was conducted among a stratified random sample of 303 recently married couples (606 individuals). Of the eligible individuals, $70 \%$ $(n=380)$ participated. Of the respondents, $73 \%$ had a positive attitude toward a routine offer of preconceptional CF carrier screening, and $56 \%$ had the intention to participate in a screening program. A positive intention to have the test was associated with high perceived anticipation of regret, intended preconceptional behavior, high perceived pressure from experts, high perceived consequences of the test results, low perceived barriers, and low perceived negative consequences for family members. These results suggest that the offer of routine preconceptional CF carrier screening would lead to substantial acceptance among couples planning a pregnancy. Several variables related with intention were identified.
\end{abstract}

\section{INTRODUCTION}

C YSTIC FIBROSIS (CF) is the most common severe autosomal recessive disorder in Caucasians, affecting approximately 1 in 2500-4000 live births. The clinical expression of CF varies; however, the disease in its classic form remains one of chronic pulmonary disease and pancreatic insufficiency. Due to improved treatment, the long-term prognosis for patients with $\mathrm{CF}$ has greatly improved over the years. However, there is still no cure for $\mathrm{CF}$.

The identification of the CF gene has made carrier screening of large populations feasible (Rommens et al., 1989). Couples in which both partners are a carrier have a 1-in-4 risk of a child with $\mathrm{CF}$ in each pregnancy. Because only a few CF carriers have a family history of $\mathrm{CF}$, in the absence of population screening most carriers do not know that they are at risk. Screening couples planning a pregnancy or pregnant women and their partners would provide an opportunity to identify carrier couples without a family history of CF and to inform these couples about their risk and about the reproductive options that are available. The aim of preconceptional/prenatal genetic screen- ing-reproductive autonomy - is different from the aim of most screening programs, i.e., preventing, treating, and alleviating disease. In genetic screening, an informed decision making should be the primary goal. That implies that a high uptake rate should not be pursued, but other parameters of success are needed (Marteau et al., 2001).

Before the development of a genetic screening program is justified, the screening should meet some general criteria (Williamson, 1993; Henneman et al., 2002; Grody, 2003). Overall, CF carrier screening meets the prerequisites that justify genetic screening: (1) CF is an important health problem, (2) screening offers carrier couples a range of reproductive options, and (3) there is a suitable test available. Furthermore, earlier research indicated that cost considerations need not be an important barrier (Wildhagen et al., 1998; Nielsen and GyrdHansen, 2002).

In most countries, CF carrier screening is not included in standard medical care, although support for screening is growing. In 1999, the National Institutes of Health recommended that CF screening should be offered to all pregnant women and couples planning a pregnancy (National Institutes of Health,

Departments of ${ }^{1}$ Clinical Genetics and Human Genetics, ${ }^{2}$ Social Medicine, ${ }^{3}$ Clinical Epidemiology and Biostatistics, VU University Medical Center, Amsterdam.

${ }^{4}$ Centre for Quality of Care Research (WOK), University of Nijmegen, The Netherlands. 
1999). In 1998, representatives of the American College of Obstetricians and Gynecologists, the American College of Medical Genetics, and other professional organisations, participated in a workshop on the implementation of CF testing. As a result of this workshop, a committee was formed to develop specific recommendations for $\mathrm{CF}$ testing. This committee encouraged preconceptional CF carrier screening whenever possible of nonJewish Caucasians and Ashkenazi Jewish couples, although they recognized that for practical purposes testing will often occur prenatally (Grody et al., 2001).

Preconceptional screening has several advantages over prenatal screening, because it provides more reproductive options and less time constraints when decisions about prenatal diagnosis have to be made. A disadvantage of preconceptional screening is that the target group is difficult to reach in the absence of established preconceptional care services, in contrast to prenatal CF carrier screening, which can relatively easy be incorporated into existing prenatal screening programs.

In the Netherlands, neither prenatal nor preconceptional CF carrier screening are standard medical care. The high percentage of planned pregnancies (85\%) (De Walle et al., 1999) makes preconceptional screening a suitable option in this country. Moreover, pregnant women present themselves late to the physician, making prenatal screening a less favorable option. A pilot project has recently been carried out (Henneman et al., 2003). In that study, individuals aged 20-35 years were invited by mail to participate in a CF carrier screening program with their partner if they were planning a pregnancy. The participation rate varied between $10 \%$ and $25 \%$ among those couples planning a pregnancy. Overall, $69 \%$ of the nonparticipants and $89 \%$ of the participants believed that screening should routinely be offered to couples planning a pregnancy. However, because this study was carried out in a small area of the country, attitudes may be different if the screening were to be implemented on a larger scale.

To develop effective implementation strategies, it is important to identify obstacles to change (Grol, 1997). Attitudes and opinions of the target population with regard to CF carrier screening are very important variables that will exert a major influence on the outcome of efforts to incorporate CF carrier screening in the health-care system. Favorable attitudes have been reported among selected groups (e.g., school pupils/students, readers of a local newspaper, recent parents, people attending a family planning clinic) and within the community in general (Ten Kate and Tijmstra, 1989; Williamson et al., 1989; Cobb et al., 1991; Watson et al., 1991a; Green, 1992; Magnay et al., 1992). However, none of the studies concentrated on the target population for preconceptional screening, i.e., couples planning a pregnancy. The National Institutes of Health (1999) concluded that there is little justification for testing all individuals, and screening should be limited to the prenatal population and couples planning a pregnancy. So far only one pilot study was aimed exclusively at couples planning a pregnancy (Henneman et al., 2003), whereas the other preconceptional pilot studies were aimed at all people of reproductive age (Watson et al., 1991b; Bekker et al., 1993; Tambor et al., 1994; Clayton et al., 1996; Payne et al., 1997; Honnor et al., 2000). Furthermore, a disadvantage of obtaining information about underlying attitudes combined with an actual offer of screening may, according to the theory of cognitive dissonance, cause bias of the results, because those participating in the screening program may feel that they ought to be positive about the screening to justify their choice (Green, 1992).

The aim of this study was to investigate the attitudes and intentions of individuals planning a pregnancy with regard to preconceptional CF carrier screening, and to identify variables that were associated with a positive and negative/neutral intention to have the test. This information can be used in the development of an implementation strategy for $\mathrm{CF}$ carrier screening on a larger scale.

\section{MATERIALS AND METHODS}

\section{Sample}

A survey, based on a questionnaire, was conducted between October, 2001, and April, 2002, among a stratified random sample of recently married couples. This group was selected because the percentage of couples planning a pregnancy (the target population of the screening program) is high among recently married couples, and they are a much more accessible population than nonmarried couples who are planning a pregnancy. Six municipalities were asked to select the names and addresses of 50 recently married couples of whom the woman was under 36 years of age. One of these municipalities selected 53 recently married couples, resulting in a total of 303 couples. Both partners in these couples $(n=606)$ received a questionnaire. They were asked to answer all questions only if they were planning a pregnancy. Couples who were not planning a pregnancy were asked to return the questionnaire, but only to answer the question "Are you planning to have children?". The municipalities were spread over the country and stratified according to religion and degree of urbanization. The goal of this stratification was to guarantee inclusion of people from municipalities with different degrees of urbanization and of people with different religions.

Follow-up included a brief reminder after 1 week, a second reminder after 1 month, again enclosing a questionnaire, and a phone-call reminder after 2 months. Respondents were offered 10 EUR if they completed the questionnaire.

Thirty-one recently married couples were excluded: 3 had been divorced, 1 was too old, 20 couples were not planning a pregnancy, and for 7 couples the questionnaires were returned as undeliverable. The response rate of the remaining individuals was $70 \%$ (380/544), with only small differences in response between men and women $(67 \%$ among men and $72 \%$ among women).

\section{The survey instrument}

A questionnaire was developed specifically for this study. The selection of variables to be included in the questionnaire was based on the results of a focus group study (Poppelaars et $a l ., 2003$ ), as well as on a review of the relevant literature. The questionnaire was pretested among 14 individuals planning a pregnancy. The final version was developed in consensus with members of an expert panel.

The questionnaire started with a short introduction explaining the disease, the hereditary nature of the disorder, the $\mathrm{CF}$ carrier test, the consequences of the different test results, and a 
short summary of the results of a pilot study in the Netherlands (Henneman et al., 2003) (see Appendix A). The information was approved by the Public Relations and Education Section, and the Medical Ethics Committee of the VU University Medical Center. After this information, the items summarized in Appendix B were listed. Some of the items were combined to form scales. The following information was collected: sociodemographic data (age, gender, level of education, religion, religious activity, and existing children), perceived barriers, perceived consequences of test results, perceived discrimination, perceived susceptibility, decision-making behavior, preconceptional behavior, perceived social influences, familiarity with $\mathrm{CF}$, perceived severity of $\mathrm{CF}$, perceived test reliability, perceived consequences for own health, perceived consequences for family members, perceived pressure from experts, perceived anticipation of regret, and perceived social pressure. The attitude of the participants toward CF carrier screening was assessed by asking them whether they agreed with the following statements: 'A CF carrier test should routinely be offered to couples planning a pregnancy,' and 'Couples should be informed about the possibility of having a CF carrier test, so that they can decide for themselves whether or not they wish to participate.'

Information about their intentions was obtained by asking 'If the currently available CF carrier test was routinely offered to couples planning a pregnancy, would you participate?' In most cases, the respondents were asked to indicate the extent to which they agreed with a statement on a 5-point Likert scale, ranging from fully disagree (1) to fully agree (5), from very low (1) to very high (5), or from definitely no (1) to definitely yes (5). Familiarity with $\mathrm{CF}$ was a yes/no option.

The questionnaire concentrated on preconceptional CF carrier screening. Subjects were not asked whether they preferred preconceptional to prenatal screening.

\section{Data analysis}

Both partners in a couple were treated as independent participants because earlier research showed that partners provide different information (Henneman et al., 2001; Newman et al., 2002).

Reliability analysis was performed on each of the scales mentioned in Appendix B to determine whether the set of items was homogeneous (Cronbach's alpha $\geq 0.60$ ). The items of each scale were added together to form a total score. To make scale scores comparable, each total score was divided by the number of items in the scale, resulting in a score ranging between 1 and 5.

To compare the variables listed in Appendix B, positive intentions to have the test were tested against negative/neutral intentions to have the test by means of a $t$ test. This was done on the whole sample $(n=380)$.

For the development of a multiple logistic regression model, the data were divided into two randomly selected samples, a first sample (sample A) of 100 observations and a second sample (sample B) of the remaining $(n=280)$ observations. Sample A was used to examine the association between a positive intention to have the test and the variables mentioned in Appendix $\mathrm{B}$, and also the sociodemographic variables, using univariate logistic regression analysis. All the variables with a $p<$
0.1 in univariate analyses were entered into the multiple logistic regression model. The resulting model was tested in sample B for confirmation. Finally, the variables which contributed significantly in both samples $(p<0.05)$, were considered to pertain to a positive intention. To be able to assess the strength of the associations, these variables were dichotomized (fully agree and agree were taken together, as were fully disagree, disagree, and neutral). Scale scores were dichotomized by the median. Of these dichotomous variables, the odds ratios and confidence intervals were calculated for the whole group of respondents $(n=380)$, using multiple logistic regression analysis. Data were analyzed using SPSS 9.0 for Windows.

\section{RESULTS}

\section{Demographic characteristics}

Table 1 shows the sociodemographic characteristics of the respondents. In total, 180 couples and 20 individuals responded. Due to stratification according to religion and the selection of married couples only, the percentages of Catholic, Dutch Reformed, Reformed, and nonreligious individuals were more equaly divided in the research group, compared to the 18- to 35 -year-old general population and, consequently, the percentage of actively religious people was higher in the research group.

\section{Attitudes toward CF carrier screening}

Seventy-three percent of the respondents (fully) agreed that a CF carrier test should routinely be offered to couples planning a pregnancy, $11 \%$ were unsure, and $16 \%$ (fully) disagreed. Overall, 93\% (fully) agreed with the statement that 'Couples should be informed about the possibility of having a CF carrier test, so that they can decide for themselves whether or not they wish to participate.'

\section{Intentions}

With regard to the question 'If the currently available $\mathrm{CF}$ carrier test was routinely offered to couples planning a pregnancy, would you participate?' the percentage of couples who answered '(probably) yes' was 56\%, 27\% were unsure, and $17 \%$ answered that they would '(probably) not' participate.

\section{Factors associated with the intentions of individuals planning a pregnancy}

Table 2 shows the univariate associations between positive and negative/neutral intentions to participate in CF carrier screening among respondents and the variables mentioned in Appendix B. Regardless of their intentions, the mean scores were high (implying that many respondents were in agreement) for: high perceived severity of $\mathrm{CF}$, high perceived test reliability, and low perceived social pressure. Furthermore, $58 \%$ of all the respondents mentioned that they were afraid of $\mathrm{CF}$ carrier discrimination by insurance companies; however, this was not significantly related to their intentions (data not shown).

The results of the multiple logistic regression analyses are shown in Table 3. Respondents with a positive intention to have the test, compared to respondents with a negative/neutral in- 
Table 1. Sociodemographic Characteristics of the Respondents Compared to the General Population

\begin{tabular}{llc}
\hline & $\begin{array}{c}\text { Respondents } \\
(\mathrm{n}=380)\end{array}$ & $\begin{array}{c}\text { General population } \\
(18-35 \text { years of age })^{\mathrm{a}}\end{array}$ \\
\hline Men, \% $(n)$ & $48(183)$ & \\
Age men (mean (range) & $29(19-51)$ & \\
Age women (mean (range) & $26(19-35)$ & \\
Having children (\% yes) & 18 & $29^{\mathrm{c}}$ \\
Level of education $(\%)^{\mathrm{b}}$ & 20 & $43^{\mathrm{c}}$ \\
Low & 48 & $28^{\mathrm{c}}$ \\
Medium & 32 & 49 \\
High & 32 & 26 \\
Religion (\%) & 19 & 9 \\
None & 21 & 7 \\
Catholic & 22 & 9 \\
Dutch Reformed & 6 & 12 \\
Reformed & & 13 \\
Other & 19 & 75 \\
Religious activity (\%) & 28 & \\
Very active & 53 & $42^{\mathrm{e}}$ \\
Moderately active & & $17^{\mathrm{e}}$ \\
Inactive/nonreligious & 48 & $41^{\mathrm{e}}$ \\
Degree of urbanization $(\%)^{\mathrm{d}}$ & 16 & \\
Low & 36 & \\
Moderate & $2001)$ & \\
High & &
\end{tabular}

aData from Statistics Netherlands (CBS, 2001).

bLow, Primary school, lower level of secondary school, or lower vocational training; medium, higher level of secondary school or intermediate vocational training; high, higher vocational training or university.

${ }^{c}$ Level of education of the general population from 25 to 44 years of age (CBS, 2001).

dLow, $<1000$ inhabitants per $\mathrm{km}^{2}$; moderate, 1000-1500 inhabitants per $\mathrm{km}^{2}$; high, $>1500$ inhabitants per $\mathrm{km}^{2}$.

eDegree of urbanization of total Dutch population (CBS, 2001).

tention, were more often afraid that they would regret it if they did not participate, more often had the intention to adopt certain preconceptional behavior (e.g., periconceptional folic acid supplementation), more often thought that the test was important because it was offered, perceived higher positive consequences of the test results (e.g., more certainty, reassurance, avoidance of the birth of a child with $\mathrm{CF}$ ), perceived less barriers (e.g., anxiety, medicalization), and perceived less difficulty in informing family members about their increased risk if they were a carrier.

\section{Perceived consequences of the test result}

Because a high percentage of respondents indicated that they were against the abortion of a child with $\mathrm{CF}(64 \%)$ and/or that the test result would not influence their reproductive behavior (34\%), items related to 'perceived consequences of test results' were analyzed in more detail. Respondents who were against the abortion of an affected fetus were more often very actively religious; $97 \%$ of the very actively religious people, $68 \%$ of the moderately actively religious people, and $49 \%$ of the inactively religious and nonreligious people were against the abortion of a child with $\mathrm{CF}$.

In the group of respondents with a positive intention to have the test, $54 \%$ were against the abortion of a child with CF, $68 \%$ wanted to avoid the birth of an affected child, and $19 \%$ were still unsure. Remarkably, $21 \%$ of those with a positive intention indicated that the test result would not influence their reproductive behavior. Reasons in favor of the test, mentioned in this group $(n=44)$ were: 'for reassurance' (77\%), 'the test is important because it is offered' $(68 \%)$ ), 'I would like to have more certainty about my chance of having a child with $\mathrm{CF}$ ' (55\%), 'I want to avoid the birth of a child with CF' (46\%), and 'If I do not participate, I am afraid I will regret it later' $(41 \%)$.

\section{DISCUSSION}

\section{Attitudes toward CF carrier screening}

From this study it appears that many couples planning a pregnancy favor the offer of routine preconceptional CF carrier testing. Informing the target population was preferred over routinely offering $\mathrm{CF}$ carrier screening, as $93 \%$ favored informing the target population and $73 \%$ favored a routine offer. The difference between offering screening and informing the target population was not further explained in the information provided to the subjects. Similar results were found for potential providers of the screening (Poppelaars et al., 2004). This 
Table 2. Univariate Associations Between Positive and Negative/Neutral Intentions to Participation among Respondents and Variables Mentioned in Appendix B

\begin{tabular}{lccc}
\hline & $\begin{array}{c}\text { Positive intention } \\
(\mathrm{n}=215) \\
\left(\text { mean }^{\mathrm{a}}\right)\end{array}$ & $\begin{array}{c}\text { Negative/neutral } \\
\text { intention } \\
(\mathrm{n}=165) \\
\left(\text { mean }^{\mathrm{a}}\right)\end{array}$ & 2.95 \\
Variable & 3.60 & 2.56 & $\mathrm{p}$ value \\
\hline Low perceived barriers & 3.44 & 3.63 & $<0.001$ \\
High perceived consequences of test result & 3.94 & 3.03 & $<0.001$ \\
High perceived test reliability & 3.73 & 3.19 & $<0.001$ \\
Intended preconceptional behavior & 3.90 & 2.29 & $<0.001$ \\
High perceived pressure from experts & 3.43 & 3.33 & $<0.001$ \\
High perceived anticipation of regret & 3.71 & 3.70 & 0.001 \\
Low perceived negative consequences & & 4.27 & 0.001 \\
for family members & 3.91 & 3.23 & 0.003 \\
High decision-making behavior & 4.46 & & 0.010 \\
High perceived severity of CF & 3.52 & 2.79 & 0.015 \\
Low perceived negative consequences & & 2.53 & 0.067 \\
for own health & 2.62 & 4.20 & 0.108 \\
High perceived social influences & 2.67 & 3.04 & 0.145 \\
High perceived susceptibility & 4.10 & & 0.161 \\
Low perceived social pressue & 2.90 & & \\
Low perceived discrimination & & & \\
\hline
\end{tabular}

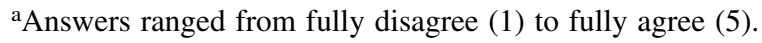

suggests that responders support informing the target population without being directive, to guarantee that they make an informed decision based on sufficient knowledge and their own attitudes. The positive attitude is in agreement with earlier research within the general population (Ten Kate and Tijmstra, 1989; Williamson et al., 1989; Cobb et al., 1991; Watson et al., 1991a; Green, 1992; Magnay et al., 1992).

\section{Factors associated with intention}

Noteworthy is the relatively high percentage $(21 \%)$ of couples who would be willing to participate, but stated that they would not change their reproductive plans (for example, by means of prenatal diagnosis, or not planning to have more children) because of their test results. It is unclear whether these couples really understood the implications of CF carrier screening, because $46 \%$ of them stated they wanted to avoid the birth of a child with CF. How would they do that if the test result would not influence their reproductive behavior? However, if they understood the implications of the screening program well, they should have other reasons for their participation than to prevent the birth of a child with $\mathrm{CF}$, e.g., 'anticipation of regret' or 'perceived pressure from experts.'

Participation to prevent regrets about decision making is a known phenomenon in medical screening and treatment (Tijmstra, 1989). 'Perceived pressure from experts has also been reported. Research among pregnant women showed that an important reason for participating in a CF screening program was the fact that they valued any tests during pregnancy (Cuckle $e t$ al., 1996; Harris et al., 1996). Patients may interpret the offer of a test as a strong recommendation, which is in contrast to the primary goal of genetic screening. Couples should only participate if they are convinced that screening is to their benefit. It is debatable whether people should participate if they are not willing to change their reproductive plans. If the autonomy of the individual is the guiding ethical principle, the choice with regard to other benefits (e.g., reassurance, preventing anticipated regret) should also be respected.

Intended preconceptional behavior was associated with a positive intention to participate. The introduction of preconceptional care settings, where people who are planning a pregnancy are informed about risk factors in pregnancy (e.g., alco-

Table 3. Multiple Logistic Regression: Significant Variables Associated with a Positive Intention of Couples Toward Participation in a CF Carrier Screening Program

\begin{tabular}{lcc}
\hline Variable & Odds ratio & 95\% Confidence interval \\
\hline High perceived anticipation of regret & 5.5 & $2.9-10.6$ \\
Intended preconceptional behavior & 3.0 & $1.7-5.2$ \\
High perceived pressure from experts & 2.8 & $1.6-4.7$ \\
High perceived consequences of test results & 2.7 & $1.5-4.8$ \\
Low perceived barriers & 2.5 & $1.5-4.4$ \\
Low perceived negative consequences for family members & 2.3 & $1.3-4.0$ \\
\hline
\end{tabular}


hol, smoking, hereditary disorders) and health promotion (e.g., folic acid supplementation), may therefore be of interest to the target population (Czeizel, 1999; De Weerd et al., 2002a). Although evidence for the effectiveness of preconceptional care is growing, some implementation barriers exist: (1) the allocation of such care in the health service systems is not clear, (2) in some countries the rates of unintended pregnancies are high, and (3) most health-care providers currently lack the appropriate knowledge (Allaire and Cefalo, 1998; De Weerd and Steegers, 2002b).

As expected, high perceived positive consequences of test results were associated with a positive intention to participate. Positive consequences of testing reflect the expectations of couples that the test result will help them to avoid the birth of a child with $\mathrm{CF}$, reassure them, or give them more certainty. This is in agreement with earlier research, which showed that an important reason for people to participate is to prevent the birth of a child with CF, whereas important reasons against participation are objections to the abortion of a child with $\mathrm{CF}$ and unwillingness to change reproductive plans (Livingstone et al., 1993; Mennie et al., 1993a; Loader et al., 1996; Witt et al., 1996, Payne et al., 1997; Henneman et al., 2003).

Low perceived barriers were also associated with a positive intention to participate. The scale 'perceived barriers' represents the expected psychosocial harm and anxiety the implementation of a $\mathrm{CF}$ carrier screening program might cause, and the burden it may represent. Increased fear of these psychosocial barriers may result in a negative intention to have the test.

Furthermore, low perceived negative consequences for family members was associated with a positive intention to participate. Informing family members was not found to be an important problem for most participants in various pilot studies (Watson et al., 1992; Mennie et al., 1993b). Mennie et al. (1993b) asked carriers and noncarriers (who were asked to imagine that they were carriers) if they would inform their relatives about their increased risk. Carriers were more likely than noncarriers to inform their relatives. The authors suggested that this may be due to post-test counseling of carriers and/or to the availability of leaflets informing carriers.

\section{Factors not associated with intentions}

The expressed concern about discrimination of CF carriers by insurance companies may be related to the continuing discussions about possible changes in health insurance. Although, at present health insurance companies do not discriminate against CF carriers, people might be unsure about future developments. The introduction of a basic health insurance policy securing access for all individuals is now under discussion in the Netherlands, which would prevent discrimination against carriers by health insurance companies.

In contrast to the results of other research, but in accordance with the findings of a Dutch pilot study (Henneman et al., 2001), no associations were found between a positive intention to participate and level of education, or perceived susceptibility (Tambor et al., 1994; Loader et al., 1996; Witt et al., 1996; Honnor et al., 2000). As was reported in earlier research, no association was found between perceived severity of $\mathrm{CF}$ and intention/participation in screening, whereas almost all respon- dents perceived CF as a serious disease (Tambor et al., 1994; Henneman et al., 2001).

\section{Translating intention into behavior}

Caution must be exercised in equating a positive intention to a likelihood that people will participate in testing. Clayton et al. (1996) showed that only $2 \%$ of the respondents who mentioned that they would accept an offer of free carrier screening for common genetic disorders actually submitted blood samples when offered free CF carrier screening. However, pilot studies have reported higher uptake rates in preconceptional CF carrier screening (Watson et al., 1991b; Bekker et al., 1993; Payne et al., 1997; Henneman et al., 2003). Uptake rates ranged from $10-20 \%$ if invited by letter to $66-87 \%$ among patients offered screening active opportunistically.

\section{Limitations of this study}

This study was performed in The Netherlands. However, attitudes and intentions may be different in other countries, where there are other cultures and religions. Furthermore, the target population for the screening (couples planning a pregnancy) differs from the respondents in this study (recently married couples). In The Netherlands, $36 \%$ of first-born children are from nonmarried couples (CBS, 2001). Moreover, couples were stratified according to religion and therefore the percentage of (actively) religious people is higher in the study population than in the general population, which may be an explanation for the fact that a high percentage of respondents was against abortion. Furthermore, in other countries the proportion of planned pregnancies might be lower. Prenatal screening may be considered additional to preconceptional screening for unplanned pregnancies.

\section{Recommendations for the implementation}

An implementation plan should include interventions to avoid or reduce any possible obstacles and adverse effects of a $\mathrm{CF}$ carrier screening program. It is important to ensure informed decision-making, instead of general acceptance of any offer. Therefore, pre-test counseling should be included in the screening program. An informed choice should be based on relevant knowledge and is consistent with the decision-maker's attitude and behavior (Marteau et al., 2001). To ensure that people with a positive intention toward carrier screening will actually participate, the barriers to testing (traveling distance, costs, limited openings hours) should be limited, because perceived discomfort was found to be the strongest predictor for nonparticipation in earlier research (Henneman et al., 2001).

The fear that the implementation of a CF carrier screening program may cause psychosocial harm and anxiety at the time of planning a pregnancy might be reduced by educational programs (such as school education programs and mass media campaigns) aimed at the general population.

Some individuals expect that they will find it difficult to inform family members if they are found to be a carrier. Post-test counseling or leaflets informing carriers about the increased risk and screening procedures for relatives may help to reduce this problem. Leaflets containing information for family members will also be necessary. Furthermore, it might be of interest to 
the target population to include $\mathrm{CF}$ carrier screening in (future) preconceptional health care. Preconception care should consist of risk assessment, health promotion, and interventions to reduce adverse pregnancy outcome.

Because no data about the reproductive choices of CF carrier couples obtained from preconceptional screening are available, long-term monitoring of the screening process will be necesarry to obtain this information.

\section{ACKNOWLEDGMENTS}

The Health Research and Development Council in the Netherlands funded this project (ZonMw grant no. 23000012). The authors wish to thank all the people who took part in this study.

\section{REFERENCES}

ALLAIRE, A.D., and CEFALO, R.C. (1998). Preconceptional health care model. Eur. J. Obstet. Gynecol. Reprod. Biol. 78, 163-168.

BEKKER, H., MODELL, M., DENNISS, G., SILVER, A., MATHEW, C., BOBROW, M., and MARTEAU, T. (1993). Uptake of cystic fibrosis in primary care: supply push or demand pull? Br. Med. J. 306, $1584-1586$.

CBS. (2001). Statistics Netherlands. http://www.statline.cbs.nl.

CLAYTON, E.W., HANNIG, V.L., PFOTENHAUER, J.P., PARKER, R.A., CAMPBELL, P.W., and PHILLIPS, J.A. (1996). Lack of interest by nonpregnant couples in population-based cystic fibrosis carrier screening. Am. J. Hum. Genet. 58, 617-627.

COBB, E., HOLLOWAY, S., ELTON, R., and RAEBURN, J.A. (1991). What do young people think about screening for cystic fibrosis? J. Med. Genet. 28, 322-324.

CUCKLE, H., QUIRKE, P., SEHMI, I., LEWIS, F., MURRAY, J., CROSS, D., CUCKLE, P., and OZOLS, B. (1996). Antenatal screening for cystic fibrosis. Br. J. Obstet. Gynaecol. 103, 795-799.

CZEIZEL, A.E. (1999). Ten years of experience in periconceptional care. Eur. J. Obstet. Gynecol. Reprod. Biol. 84, 43-49.

DE WALLE, H.E., DE JONG-VAN DEN BERG, L.T., and CORNEL, M.C. (1999). Periconceptional folic acid intake in the northern Netherlands. Lancet 353, 1187.

DE WEERD, S., THOMAS, C.M.G., CIKOT, R.J.L.M., STEEGERSTHEUNISSEN, R.P.M., DE BOO, T.M., and STEEGERS, E.A.P. (2002a). Preconception counseling improves folate status of women planning pregnancy. Obstet. Gynecol. 99, 45-50.

DE WEERD, S., and STEEGERS, E.A.P. (2002b). The past and present practices and continuing controversies of preconception care. Community Genet. 5, 50-60.

GREEN, J.M. (1992). Principles and practicalities of carrier screening: attitudes of recent parents. J. Med. Genet. 29, 313-319.

GRODY, W.W. (2003). Molecular genetic risk screening. Annu. Rev. Med. 54, 473-490.

GRODY, W.W., CUTTING, G.R., KLINGER, K.W., RICHARDS, C.S., WATSON, M.S., and DESNICK, R.J. (2001). Laboratory standards and guidelines for population-based cystic fibrosis carrier screening. Genet. Med. 3, 149-154.

GROL, R. (1997). Beliefs and evidence in changing clinical practice. Br. Med. J. 315, 418-421.

HARRIS, H., WALlACE, A., SCOTCHER, D., CRAUFURD, D., HARTLEY, N., and HARRIS, R. (1996). Pilot study of the acceptability of cystic fibrosis carrier testing during routine antenatal consultations in general practice. Br. J. Gen. Pract. 46, 225-227.

HENNEMAN, L., BRAMSEN, I., VAN DER PLOEG, H.M., ADER, H.J., VAN DER HORST, H.E., GILLE, J.J.P., and TEN KATE, L.P. (2001). Participation in preconceptional carrier couple screening: characteristics, and knowledge of both partners. J. Med. Genet. 38, 695-703.

HENNEMAN, L., POPPELAARS, F.A.M., and TEN KATE, L.P. (2002). Evaluation of cystic fibrosis carrier screening programs according to genetic screening criteria. Genet. Med. 4, 241-249.

HENNEMAN, L., BRAMSEN, I., VAN KEMPEN, L., VAN ACKER, M.B., PALS, G., VAN DER HORST, H.E., ADÈR, H.J., VAN DER PLOEG, H.M., and TEN KATE, L.P. (2003). Offering preconceptional cystic fibrosis carrier couple screening in the absence of established preconceptional care services. Community Genet. 6, 5-13.

HONNOR, M., ZUBRICK, S.R., WALPOLE, I., BOWER, C., and GOLDBLATT, J. (2000). Population screening for cystic fibrosis in Western Australia: community response. Am. J. Med. Genet. 93, 198-204.

LIVINGSTONE, J., AXTON, R.A., MENNIE, M., GILFILLAN, A., and BROCK, D.J.H. (1993). A preliminary trial of couple screening for cystic fibrosis: designing an appropriate information leaflet. Clin. Genet. 43, 57-62.

LOADER, S., CALDWELL, P., KOZYRA, A., LEVENKRON, J.C., BOEHM, C.D., KAZAZIAN, H.H., and ROWLEY, P.T. (1996). Cystic fibrosis carrier population screening in the primary care setting. Am. J. Hum. Genet. 59, 234-247.

MAGNAY, D., WILSON, O., EL HAIT, S., BALHAMAR, M., and BURN, J. (1992). Carrier testing for cystic fibrosis: knowledge and attitudes within a local community. J. R. Coll. Physicians. Lond. 26, 69-70.

MARTEAU, T.M., DORMANDY, E., and MICHIE, S. (2001). A measure of informed choice. Health Expect. 4, 99-108.

MENNIE, M.E., GILFILLAN, A., COMPTON, M.E., LISTON, W.A., and BROCK, D.J.H. (1993a). Prenatal cystic fibrosis carrier screening: factors in a woman's decision to decline testing. Prenat. Diagn. 13, 807-814.

MENNIE, M., COMPTON, M., GILFILLAN, A., AXTON, R.A., LISTON, W.A., PULLEN, I., WHITE, D., and BROCK, D.J.H. (1993b). Prenatal screening for cystic fibrosis: attitudes and responses of participants. Clin. Genet. 44, 102-106.

NATIONAL INSTITUTES OF HEALTH. (1999). Genetic testing for cystic fibrosis. National Institutes of Health Consensus Development Conference Statement on genetic testing for cystic fibrosis. Arch. Intern. Med. 159, 1529-1539.

NEWMAN, J.E., SORENSON, J.R., DEVELLIS, B.M., and CHEUVRONT, B. (2002) Gender differences in psychosocial reactions to cystic fibrosis carrier testing. Am. J. Med. Genet. 113, 151-157.

NIELSEN, R., and GYRD-HANSEN, D. (2002). Prenatal screening for cystic fibrosis: an economic analysis. Health Econ. 11, 285-299.

PAYNE, Y., WILLIAMS, M., CHEADLE, J., STOTT, N.C.H., ROWLANDS, M., SHICKLE, D., WEST, G., MEREDITH, L., GOODCHILD, M., HARPER, P.S., and CLARKE, A. (1997). Carrier screening for cystic fibrosis in primary care: evaluation of a project in South Wales. Clin. Genet. 51, 153-163.

POPPELAARS, F.A.M., VAN DER WAL, G., BRASPENNING, J.C.C., CORNEL, M.C., HENNEMAN, L., LANGENDAM, M.W., and TEN KATE, L.P. (2003). Possibilities and barriers in the implementation of a preconceptional screening programme for cystic fibrosis carriers: a focus group study. Public Health 117, 396-403.

POPPELAARS, F.A.M., ADER, H.J., CORNEL, M.C., HENNEMAN, L., HERMENS, R.P.M.G., VAN DER WAL, G., and TEN KATE, L.P. (2004). Attitudes of potential providers towards preconceptional cystic fibrosis carrier screening. J. Gen. Counsel. 13, 31-44.

ROMMENS, J.M., IANNUZZI, M.C., KEREM, B., DRUMM, M.L., MELMER, G., DEAN, M., ROZMAHEL, R., COLE, J.L., KENNEDY, D., HIDAKA, N., et al. (1989). Identification of the cystic fibrosis gene: chromosome walking and jumping. Science $\mathbf{2 4 5}$, 1059-1065.

TAMBOR, E.S., BERNHARDT, B.A., CHASE, G.A., FADEN, R.R., GELLER, G., HOFMAN, K.J., and HOLTZMAN, N.A. (1994). Of- 
fering cystic fibrosis carrier screening to an HMO population: factors associated with utilization. Am. J. Hum. Genet. 55, 626-637.

TEN KATE, L.P., and TIJMSTRA, T.J. (1989). Carrier screening for cystic fibrosis. Lancet 21, 973-974.

TIJMSTRA, T. (1989). The imperative character of medical technology and the meaning of "anticipated decision regret". Int. J. Technol. Assess Health Care 5, 207-213.

WATSON, E.K., WILLIAMSON, R., and CHAPPLE, J. (1991a). Attitudes to carrier screening for cystic fibrosis: a survey of health care professionals, relatives of sufferers and other members of the public. Br. J. Gen. Pract. 41, 237-240.

WATSON, E.K., MAYALL, E., CHAPPLE, J., DALZIEL, M., HARRINGTON, K., WILLIAMS, C., and WILLIAMSON, R. (1991b). Screening for carriers of cystic fibrosis through primary health care services. Br. Med. J. 303, 504-507.

WATSON, E.K., MAYALL, E.S., LAMB, J., CHAPPLE, J., and WILLIAMSON, R. (1992). Psychological and social consequences of community carrier screening programme for cystic fibrosis. Lancet 340, 217-220.

WILLIAMSON, R., ALLISON, M.E.D., BENTLEY, T.J., LIM, S.M.C., WATSON, E., CHAPPLE, J., ADAM, S., and BOULTON, M. (1989). Community attitudes to cystic fibrosis carrier testing in England: a pilot study. Prenat. Diagn. 9, 727-734.
WILLIAMSON, R. (1993). Universal community carrier screening for cystic fibrosis. Nature Genet. 3, 195-201.

WILDHAGEN, M.F., HILDERINK, H.B., VERZIJL, J.G., VERHEIJ, J.B.G.M., KOOIJ, L., TIJMSTRA, T., TEN KATE, L.P., and HABBEMA, J.D.F. (1998). Costs, effects, and savings of screening for cystic fibrosis gene carriers. J. Epidemiol. Commun. Health 52, 459-467.

WITT, D.R., SCHAEFER, C., HALLAM, P., WI, S., BLUMBERG, B., FISHBACH, A., HOLTZMAN, J., KORNFELD, S., LEE, R., NEMZER, L., and PALMER, R. (1996). Cystic fibrosis heterozygote screening in 5,161 pregnant women. Am. J. Hum. Genet. 58, 823-835.

\author{
Address reprint requests to: \\ Leo Ten Kate, M.D., Ph.D. \\ Department of Clinical Genetics and Human Genetics \\ $V U$ University Medical Center \\ P.O. Box 7057 \\ NL-1007 MB, Amsterdam \\ The Netherlands \\ E-mail:1p.tenkate@vumc.nl
}

\section{APPENDIX A INFORMATION PROVIDED TO ALL SUBJECTS}

Information about the cystic fibrosis carrier test

\section{Introduction}

Most children are born healthy. Unfortunately, there is no guarantee for a healthy child. There will always be a small risk that a child will be born with a disorder. One of the most common hereditary disorders in The Netherlands is cystic fibrosis. The cystic fibrosis carrier test makes it possible to determine whether couples have an increased risk of having a child with CF. Couples who wish to have children can be informed about their risk of having a child with CF before the pregnancy. The aim of this study is to determine whether the CF carrier test should routinely be offered to (all) couples planning a pregnancy.

\section{What is cystic fibrosis?}

Cystic fibrosis (CF) is a severe, hereditary disorder, for which there is no cure (yet). The main symptoms of CF are respiratory and digestive problems. Different organs are affected due to the production of abnormally thick mucus, which accumulates in the lungs and the pancreas. Due to thick mucus in the lungs, the lungs can become infected. Chronic lung infections, eventually, lead to the destruction of lung tissue, which makes breathing difficult. Due to thick mucus in the pancreas, less fat can be digested, resulting in fatty stools. The lungs cause the greatest problems for most CF patients, but the complaints and the resulting life-expectancy vary per patient.

CF is usually diagnosed within the first two years of life, and the symptoms vary. Some children may have only mild respiratory problems and can function more or less the same as healthy children of their own age. Other children are ill almost all the time, have to be treated by many physicians, and are unable to live a normal life. In time, most symptoms become worse. The majority of CF patients have to take medication every day, and physiotherapy and a high-energy diet are often part of the therapy. Although home treatment has improved, some hospital treatment is still necessary for most patients. The time CF patients spend on their daily treatment varies greatly, but it can be as much as several hours a day. Lung transplantation may prolong the life of CF patients when no further treatment is possible.

The total number of CF patients in The Netherlands is now estimated to be approximately 1200, and almost 500 of these are adults. In the past, most children with CF died before they reached the age of ten. Due to improved treatment, over half of the patients with CF can now expect to survive beyond the age of 35 . Although the life-expectancy of CF patients is likely to improve in the future, there is still no cure for CF.

In The Netherlands, approximately 50 children are born with CF each year. This is 1 in 3,600 newborn babies. This makes $\mathrm{CF}$ one of the most common hereditary diseases in The Netherlands. Children with CF are often born in families without previous cases of CF. The birth of a child with $\mathrm{CF}$ is therefore often totally unexpected.

\section{When does a child develop cystic fibrosis?}

All hereditary information is present in so-called genes, and every person has two copies of almost all genes: one copy from their father and one copy from their mother. Everyone has a few pairs of genes in which there is a fault (mutation) in one of the two 
genes. However, in addition to the one with the mutation, they have also a normal copy of the gene that predominates. Therefore, these people are healthy. Healthy people with a mutation in one copy of a pair of genes are called carriers. If a person has a mutation in one copy of the genes related to $\mathrm{CF}$, this person is called a CF carrier. CF carriers are healthy, they will not develop cystic fibrosis, and usually they do not even know that they are a carrier. In The Netherlands, 1 in 30 people is a CF carrier. This means that there are approximately half a million CF carriers in the Netherlands.

A child will develop CF only if both the father and the mother have a mutation in one copy of the CF genes, and both parents pass this on to the child. The child will then have two mutated copies of the CF genes.

\section{What does the CF carrier test involve?}

For the CF carrier test, a mouthwash sample needs to be collected. This involves rinsing the mouth with salt water for one minute, and then spitting this water into a bowl. Information about the genes is then extracted form the mouthwash samples, and tested.

\section{One mutated copy of the CF gene, what does that mean?}

If one of the partners is a CF carrier, it is important to know the test result of the other partner. If the other partner is not a CF carrier, the chance of having a child with $\mathrm{CF}$ is not increased. However, there is still a slight chance of having a child with $\mathrm{CF}$, because not all $\mathrm{CF}$ carriers can be detected with the $\mathrm{CF}$ carrier test.

\section{What if both partners have a mutated copy of the CF gene?}

If both partners are CF carriers, they have a 1-in-4 risk of having a child with CF in each pregnancy. These carrier couples can choose from the following options:

1. Accept the increased risk of having a child with CF.

2. Undergo a test during pregnancy to determine whether the unborn child has CF. If so, the couple can decide to:

- await the birth of the child and possibly make preparations (early plans for treatment and support of the child), or

- terminate the pregnancy (abortion)

3. In vitro fertilization with the selection of a nonaffected fertilized egg before implantation.

4. Make use of donor sperm or egg.

5. Decide not to have children.

6. Adoption.

\section{Summary of a few important issues related to cystic fibrosis carrier testing}

- On the one hand, informing couples about the CF carrier test gives them the opportunity to decide for themselves whether or not they want to have the test. On the other hand, if the test is offered to individuals who do not want to know about it, this information will be an extra burden for them.

- The chance that both partners in a couple are CF carriers is 1 in 900. If both partners are CF carriers, they have a 1-in-4 (25\%) risk in each pregnancy of having a child with CF.

- Couples wishing to have children will have the opportunity to avoid the birth of a child with CF, or to prepare for it.

- Proof that a person is a CF carrier, also means that members of their family have an increased risk of being CF carriers. Brothers and sisters of CF carriers have a 1-in-2 (50\%) risk of being CF carriers themselves. As a result of the CF carrier screening, family members with an increased risk of having a child with $\mathrm{CF}$ are traced more quickly. However, if they do not want to know, the information may be a burden.

- If the CF carrier test showed no mutation, there is still a small chance of being a CF carrier, because the test identifies not all, but approximately $95 \%$ of the CF carriers. This means that if the test showed no mutation, the risk of having a child with $\mathrm{CF}$ will be very small (approximately 1 in 70,000), but not zero. If one of the two partners is found to be a carrier, and the other one is not, the risk of having a child with $\mathrm{CF}$ decreases from 1 in 3,600 (population risk) to 1 in 6,000 .

- The life-expectancy for people with CF is improving, and the severity of symptoms varies per patient. If both partners in a couple are CF carriers, the severity of the disease can not be accurately predicted in an unborn baby.

- The CF carrier test only provides information about the risk of having a child with CF. The risk of other congenital disorders, which is approximately $2-3 \%$, remains unchanged.

\section{Results of earlier scientific research}

In a recent study that was carried out in a small area of the country, individuals aged 20-35 years received a postal invitation to participate in a $\mathrm{CF}$ carrier screening program, together with their partner, if they were planning a pregnancy. Participation was voluntary. Between $10 \%$ and $25 \%$ of all couples who were planning a pregnancy participated. Before the test, these couples were informed about the disease, the $\mathrm{CF}$ carrier test, and the reproductive options for carrier couples. They received this information either in a group educational session or during a GP consultation. The response rate was higher when information was received during a GP consultation. The main reasons given by couples for non-participation were "lack of time" and "don't want to know the test results." Satisfaction among the participants was high. 
APPENDiX B. Construct of the Questionnaire: Scales with Corresponding Items and Cronbach's Alpha $(n=7)$ and Separate Items $(n=8)$

\begin{tabular}{|c|c|c|}
\hline Variables & $\begin{array}{l}\text { Cronbach's } \\
\quad \text { alpha }\end{array}$ & Items \\
\hline \multicolumn{3}{|l|}{ Scales } \\
\hline Perceived barriers & 0.77 & $\begin{array}{l}\text { I am afriad CF screening will be the first step in developing a perfect child. } \\
\text { Offering a CF carrier test will cause anxiety in couples planning a pregnancy. } \\
\text { I am afraid that the CF carrier test will put a burden on people who don't want } \\
\text { to know about it. } \\
\text { The CF carrier test creates too high expectations of the birth of a healthy child. } \\
\text { You have to visit a physician even before you are pregnant, I don't like that. }\end{array}$ \\
\hline $\begin{array}{l}\text { Perceived consequences } \\
\text { of test results }\end{array}$ & 0.77 & $\begin{array}{l}\text { I want to avoid the birth of a child with CF. } \\
\text { The test results will not have any influence on my reproductive behavior } \\
\text { (reversed). } \\
\text { I would like to have more certainty about my chance of having a child with CF. } \\
\text { Carrier testing will me give reassurance. } \\
\text { I am against abortion of a child with CF (reversed). }\end{array}$ \\
\hline Perceived discrimination & 0.62 & $\begin{array}{l}\text { I am afraid of discrimination of CF carriers by insurance companies. } \\
\text { I am afraid of discrimination of CF carriers by the social environment. }\end{array}$ \\
\hline Perceived susceptibility & 0.83 & $\begin{array}{l}\text { Estimated likelihood of being a CF carrier. } \\
\text { Estimated likelihood of being a CF carrier couple. } \\
\text { Estimated likelihood of having a child with CF. }\end{array}$ \\
\hline Decision-making behavior & 0.60 & $\begin{array}{l}\text { I defer the making of important decisions. } \\
\text { I prefer decision making be done by people who are better informed. } \\
\text { I don't like to take responsibility for important decisions. }\end{array}$ \\
\hline Preconceptional behavior & 0.61 & $\begin{array}{l}\text { Before a pregnancy, I will go to my GP for preconceptional counselling. } \\
\text { Folic acid suppletion is important for me to reduce the risk of the birth of a } \\
\text { child with a neural tube defect. } \\
\text { If a preconceptional care center existed, I would visit it before a pregnancy. }\end{array}$ \\
\hline $\begin{array}{l}\text { Perceived social } \\
\text { influences }\end{array}$ & 0.79 & $\begin{array}{l}\text { Important in my decision to participate or not in the screening program is the } \\
\text { opinion of: } \\
\text { - my parents } \\
\text { - my GP } \\
\text { - the social environment } \\
\text { - my friends }\end{array}$ \\
\hline \multicolumn{3}{|l|}{ Single items } \\
\hline Familiarity with $\mathrm{CF}$ & & Do you know (have you known) a CF patient? \\
\hline Perceived severity of $\mathrm{CF}$ & & $\mathrm{CF}$ is a very severe disease. \\
\hline Perceived test reliability & & $\begin{array}{l}\text { A CF carrier test with a test sensitivity of } 95 \% \text { is reliable enough to use for } \\
\text { routinely screening all couples planning a pregnancy. }\end{array}$ \\
\hline $\begin{array}{l}\text { Perceived consequences } \\
\text { for own health }\end{array}$ & & If I were a carrier, I would feel less healthy. \\
\hline $\begin{array}{l}\text { Perceived consequences } \\
\text { for family members }\end{array}$ & & $\begin{array}{l}\text { If I were a carrier, I would find it difficult to inform my family members about } \\
\text { their increased risk. }\end{array}$ \\
\hline $\begin{array}{l}\text { Perceived pressure from } \\
\text { experts }\end{array}$ & & The test is important because it is offered. \\
\hline $\begin{array}{l}\text { Perceived anticipation } \\
\text { of regret }\end{array}$ & & If I do not participate, I am afraid I will regret it later. \\
\hline Perceived social pressure & & I am afraid of the reaction of other people, if I get a child with CF. \\
\hline
\end{tabular}

